\title{
KARSTIC LANDSCAPE STUDY BASED ON REMOTE SENSING DATA: THE CASE OF KSIROMERO REGION, AITOLOAKARNANIA - WESTERN GREECE
}

\author{
Golubović Deliganni M. ${ }^{1}$, Parcharidis I. ${ }^{1}$, Pavlopoulos K. ${ }^{1}$ \\ ${ }^{1}$ Harokopio University, Faculty of Geography, 70 El. Venizelou Str., 17671 Athens, Greece \\ miljanamakis@yahoo.com,parchar@hua.gr,kpavlop@hua.gr
}

\begin{abstract}
The aim of this study is to investigate and recognize karst landforms in the area of Ksiromero (Aitoloakarnania, Western Greece) based on medium resolution remote sensing data. In order to highlight karstic structures appropriate and innovative methodologies of image analysis have been developed, applied and compared. In particular, the original Landsat 5 TM bands have been, first, ad-hoc stretched and then processed to obtain the so-called Tasseled Cap Features and the Principal Component images. Finally, a comparative study between the two methods has been carried out.
\end{abstract}

Key words: Karst landscape, Landsat TM, Principal Component Analysis, Tasseled Cap, Ksiromero, Western Greece

\section{Introduction}

The characteristics of drainage networks, morphology, soil cover and other diagnostic parameters such as vegetation and moisture can be studied using multispectral satellite images. Various lithologies reflect radiation in different ways, depending on surface properties (soil, vegetation, morphology etc); consequently, evaluating such properties and their cumulative effects can lead to conclusions regarding the type and state of the lithology. Because all physical or non physical surfaces reflect the electromagnetic radiation according to their physical-chemical properties Landsat TM multispectral bands are considered particularly suitable to detect and study common features in karst areas.

This study highlights karst features in the area of Ksiromero, Aitoloakarnania, Western Greece using different image processing methods, based on spectral and spatial image enhancement.

\section{Regional and local geological setting}

Ksiromero is a region in the northern section of the Prefecture of Aitoloakarnania in western Greece (Fig.1). The region has a total area extent of $106,76 \mathrm{~km}^{2}$ and ranges in elevation from $178 \mathrm{~m}$ to 1.314 $\mathrm{m}$ above sea level. The area is within the Ionian Geotectonic Zone, part of the External Hellenides Platform that extends west from mainland Greece and appears on the western edge of Peloponnesus.

Long thrust faults that trend east-west and northeast-southwest and long reversed and normal faults that trend northwest-southeast are characteristics of the Ionian Zone. 


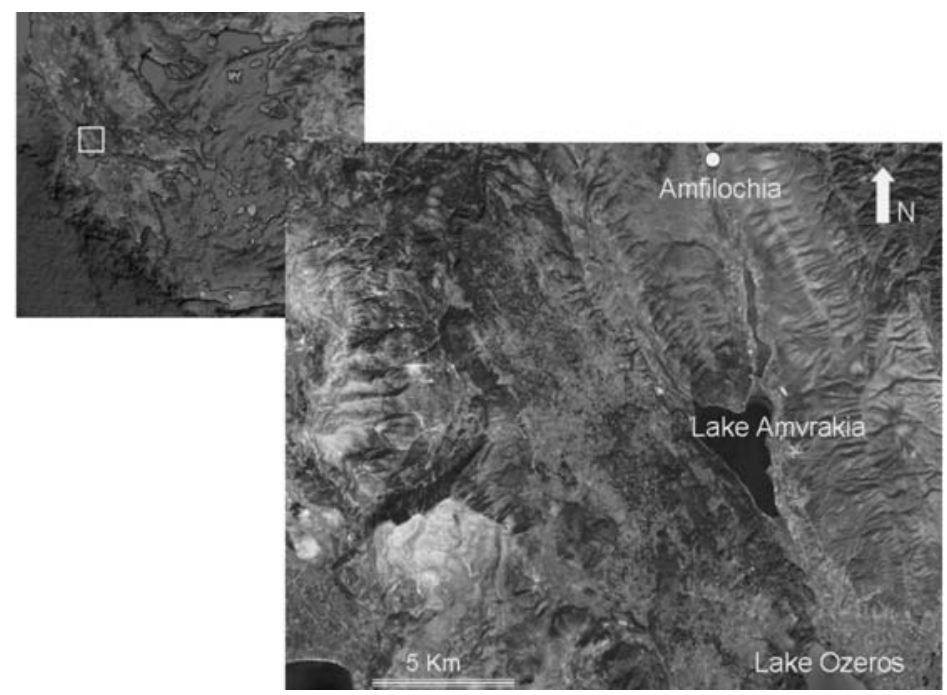

Fig.1: Location of Ksiromero area (Aitoloakarnania, Western Greece) on a very high resolution satellite image QuickBird (source: Google Earth).

During Permo-Triassic time, the Ionian Zone was a shallow, restricted, marine basin which accumulated over $150 \mathrm{~m}$ of evaporites (Karakitsios, 1992), of which gypsum is notably exposed. Their episodic deposition may have allowed the development of a paleointrastratal karst, as described in other regions by Bosak et al. (1989), although no direct evidence has been found. Triassic Tryphos Formation carbonate breccia conglomerates were deposited over the evaporites, followed by up to 200 $\mathrm{m}$ of dolomite and as much as $300 \mathrm{~m}$ of the Pantocrator Limestone into the Early Jurassic. At that time, the shallow Tethys Sea covered a continental platform which extended throughout nearly all of western Greece. The carbonate breccia conglomerates are epigenetic, formed during the Triassic from major tectonic activity, diapiric deformation and dissolution of underling evaporites. These conditions continued with small modifications up to the end of the Jurassic. From the Pliocene to the Quaternary, more recent gypsum deformation occurred at the surface due to underlying diapiric movement along prominent faults (Underhill, 1988). The Tryphos carbonate breccias are the main karstified rocks of the region. They range from 10-200 m thick and cover $70 \%$ of the area. Geologic information of the region are provided by the Institute of Geology and Mineral Exploration $(1986,1987)$.

From a geographic perspective, the region internally drains water to where it is not exploitable for use. Hydrogeologically, it is a system of closed karst watersheds whose recharge characteristics are poorly defined and where the downgradient destination of its groundwater is unknown. While recharge occurs through the higher elevation limestones and dolomites, most of it is transmitted though the Tryphos breccia and the underlying gypsum. The highly soluble gypsum matrix of the conglomerate produces a relatively uniform high-permeability surface that minimizes surface runoff. While most karst features of the region are developed in the Tryphos formation, their density may have been greater if the matrix had been carbonate. Additionally, the few open caves and conduits in the region likely result from the high production of a residual terra rossa soils, talus and debris cones from gypsum, limestones breccia and conglomerates. The soils are accumulated on all surfaces, especially in dolines and poljes, and runoff is insufficient to transport them through the karst to create more open caves. 


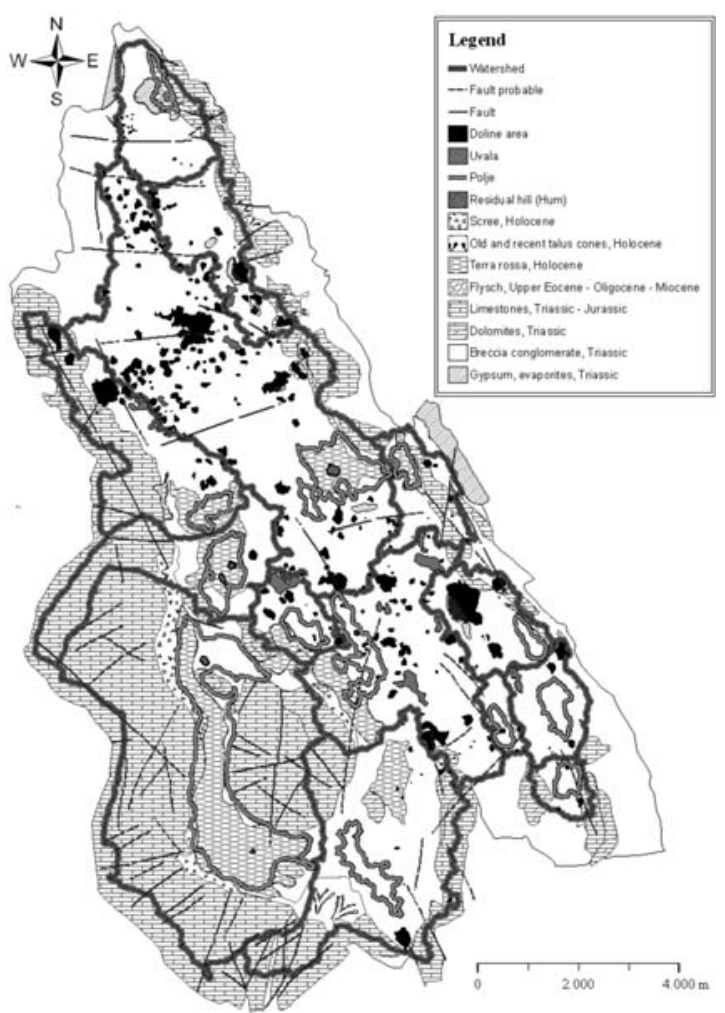

Fig.2: Karst geomorphological map Ksiromero, Aitoloakarnania, Western Greece.

\section{Karst geomorphology and and geographic information system (GIS) analysis}

To better evaluate the karst geomorphologic characteristics of Ksiromero region, this study is based on comparing of results of field research, digitalized geodetabaze of karst landforms and Landsat Satellite images. As results of karst geodatabase and geological information of the region of research we created karst geomorphologic map of Ksiromero, Aitoloakarnania, Western Greece (Fig.2: geological maps of IGME, 1986, 1987).

With use of ArcGIS Info 9.3 we created a detailed geodatabase of karst landforms and developed a mechanism for symbolically identifying the ephemeral, temporal, or inferred features common for karst in this region. All 1:5000 topographic sheets of the region were digitized at 4-m contour intervals and interpolated at $2 \mathrm{~m}$ above mean sea level to allow detailed visualization and analysis. We created a database with all existing karst forms and their sub-groups in different layers.

We identified 14 poljes in the region. Through watershed delineation, we identified one large compound karst basin, which includes nine smaller polje watersheds, and five smaller separate watersheds for poljes. We found 17 residual hills in the poljes, comprised predominantly of limestone intercalated with gypsum and likely the result of lesser solubility than tectonic factors. We identified a total of 278 dolines with funnel, shallow, and a few collapse morphologies. We also identified 12 uvalas. Ponors are rare but exist at the contact of the limestone with the breccia conglomerates and follow faults. Using Čar's (2001) classification scheme, Ksiromero primarily has broken, broken collapse, near-fault, and fault dolines. 


\section{Methodology, data used and processing}

The present study aims at enhancing the understanding of karst morphology at Ksiromero as recorded in a Landsat TM scene acquired on September 9th 1992 at 9:25 UTC time. To highlight these features, different image processing methods based on suitable statistical (spectral) and filtering (spatial) procedures were applied to the Landsat TM multispectral data. Finally a computer-aided visual comparison of the two methods of processing was used to determine which is most suitable for such application.

At first, a subset of the full scene was created covering the study area. Next, two methods of spectral enhancement were applied (i) Principal Component Analysis and (ii) Tasseled Cap Transformation.

\section{1 . Principal Component Analysis}

Principal Component Analysis (PCA) is a statistical method to produce uncorrelated output bands that segregate noise components and reduce the dimensionality of the data set (Richards, 1999). Because multispectral data bands are often highly correlated, the PCA transformation is used to produce uncorrelated output bands. This is achieved by creating a new set (principal component bands) of orthogonal axes that have their origin at the data mean and are rotated so the data variance is maximized.

The principle component bands are linear combinations of the original spectral bands and are uncorrelated. The first component coincides with the direction and length of the widest transect of the ellipse and therefore it measures the highest variation within the data. The respective image appears panchromatic with no spectral input. The second principal component is the widest transect of the ellipse perpendicular to the first component and describes the largest amount of variance not contained in the first component. The remaining principal components are similarly determined (Taylor, 1977).

We adapted Landsat satellite imaging of Ksiromero, using ERDAS Imagine 9.1 software, for PCA. Standardized principle component transformations were conducted using the six bands of the Landsat image, excluding the thermal band. We determined: $\mathrm{PC} 1=90 \%, \mathrm{PC} 2=6.5 \%, \mathrm{PC} 3=2.3 \%, \mathrm{PC} 4=$ $0.5 \%$, PC $5=0.3 \%$ and PC6 $=0.01 \%$. using the first three components we created a color image (Fig. 3 ).

\section{2 . Data analysis of Tasseled Cap Transformation}

The Tasseled Cap (TCs) features, also known as Kauth-Thomas Transforms, are utilized for enhancing spectral information content of satellite data (Kauth and Thomas, 1976). The different bands in a multispectral image can be visualized as defining an $\mathrm{N}$-dimensional space where $\mathrm{N}$ is the number of bands. Each pixel, positioned according to its DN value in each band, lies within the N-dimensional space. This pixel distribution is determined by the absorption/reflection spectra of the imaged material. This clustering of the pixels is termed the data structure (Crist and Kauth, 1986). The data structure can be considered a multidimensional hyperellipsoid. The principal axes of this data structure are not necessarily aligned with the axes of the data space (defined as the bands of the input image). They are more directly related to the absorption spectra. For viewing purposes, it is advantageous to rotate the $\mathrm{N}$-dimensional space such that one or two of the data structure axes are aligned with the Viewer $\mathrm{X}$ and $\mathrm{Y}$ axes. In particular, we could view the axes that are largest for the data structure produced by the absorption peaks of special interest for the application. 
Table 1. TC coefficients for Thematic Mapper sensor (source: ERDAS, Imagine).

\begin{tabular}{|c|c|c|c|c|c|c|}
\hline & Layer 1 & Layer 2 & Layer 3 & Layer 4 & Layer 5 & Layer 6 \\
\hline 1 & 0.3037 & 0.2793 & 0.4743 & 0.5585 & 0.5082 & 0.1863 \\
\hline 2 & -0.2848 & -0.2435 & -0.5436 & 0.7243 & 0.084 & -0.18 \\
\hline 3 & 0.1509 & 0.1973 & 0.3279 & 0.3406 & -0.7112 & -0.4572 \\
\hline 4 & 0.8832 & -0.0819 & -0.458 & -0.0032 & -0.0563 & 0.013 \\
\hline 5 & 0.0573 & 0.026 & 0.0335 & -0.1943 & 0.4766 & -0.8545 \\
\hline 6 & 0.1238 & -0.9038 & 0.4042 & 0.4041 & -0.0261 & 0.024 \\
\hline
\end{tabular}

The TCs are calculated by applying a linear affine transformation, substantially based on the conversion of given input band data set in a new data set of composite values. The transformation depends on the sensor, in this case Landsat TM. The original TCs were first derived for the four bands of the Landsat MSS sensor. Later, the TC transformation was extended to the Landsat TM/ETM (Crist and Cicone, 1984) and IKONOS sensors (Horne, 2003). As for Landsat 5 TM data the coefficients to achieve the TCs are given in Table 1.

Research has produced three data structure axes (Crist et al, 1986; Crist and Kauth, 1986):

- Brightness - a weighted sum of all bands, defined in the direction of the principal variation in soil reflectance.

- Greenness - orthogonal to brightness, a contrast between the near-infrared and visible bands; strongly related to the amount of green vegetation in the scene.

- Wetness - relates to soil moisture (Lillesand and Kiefer, 1987).

The resulting TCs covering the study area are shown in Figure 4 as false color composite image where brightness, greenness and wetness are respectively displayed as red, green and blue.

Finally, a high-pass filter was applied to make the image sharper and to highlight linear features.

\section{Conclusions-Results}

Ksiromero is a region of carbonate breccia conglomerate karst, with morphologic and hydrologic characteristics complicated by underlying evaporites and preferential dissolution of the gypsum matrix.

Karst in the carbonate breccia conglomerates has dramatic features, including richly developed fields of dolines, uvalas, and poljes but its features cannot be adequately understood based on carbonate karst conditions alone. Figure 5 and 6 overlays the karst landforms shown in with Figure 2 with the PCA and TC imagery to provide comparison of how well each delineates those landforms.

With PCA method the borders of karst forms cannot be clearly recognized, but only inferred.

We can recognize large karst features, such as the largest polje's watershed but limestone pavement and smaller karst features like dolines or uvalas are otherwise difficult or impossible to remotely discern by this method. Also some of hums are recognizable and that probably depends on the wealthier of vegetative covering, or of different geological composition of their rocks from the geological base of their poljes. We came to this conclusion because to the change of color scheme in places that corresponds to positions of hum. This is partially controlled by the spatial resolution of the satellite system used. 


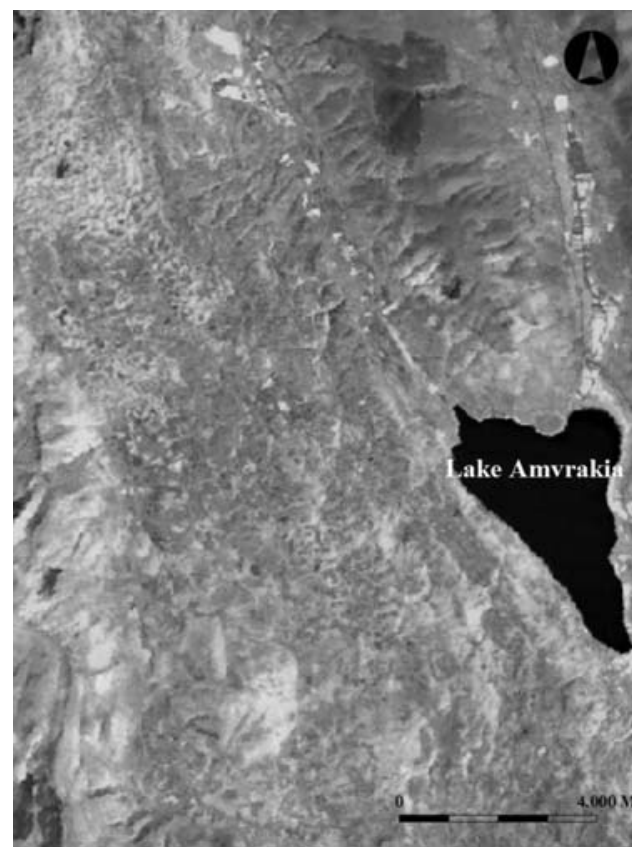

Fig. 3: PCA color image using the first three components as RGB.

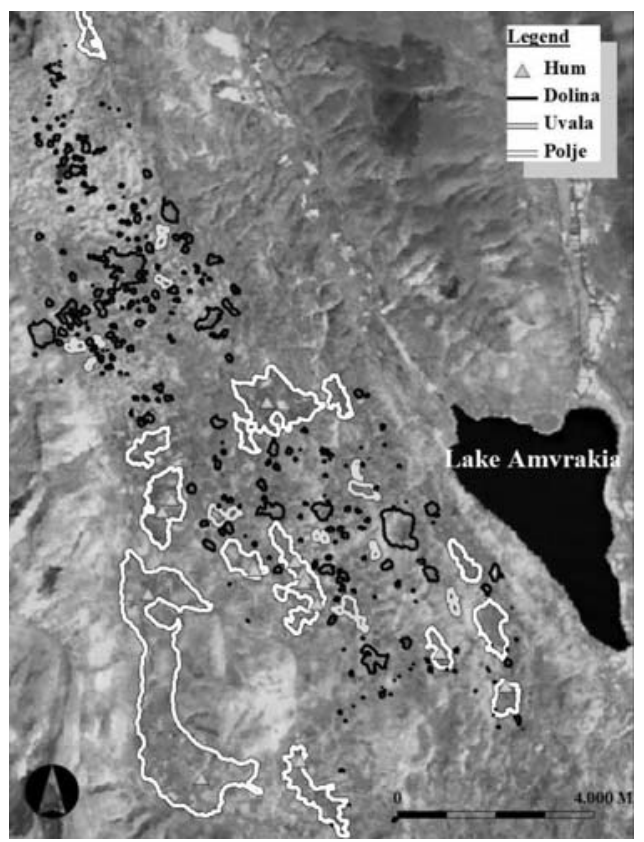

Fig. 5: PCA color image with Kast landscape features.

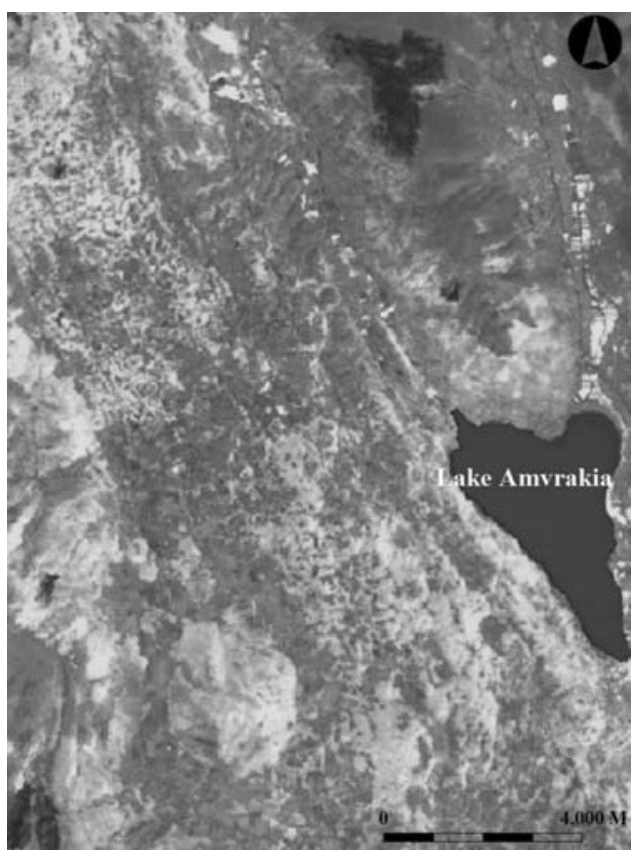

Fig. 4: Tasseled Cap color image (Brightness=Red, Greenness $=$ Green, Wetness $=$ Blue $)$.

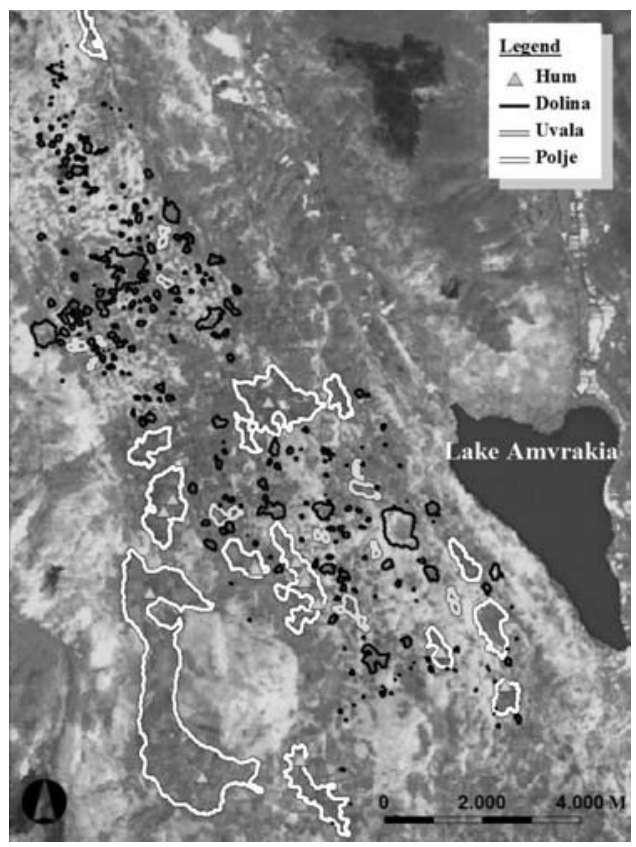

Fig. 6: TC color image with Kast landscape. 
With TCs methods the boundaries of some karst forms are more easily mapped and some are even sharply defined.

Also, if we compare the geological map of the study area with the TCs satellite image, the difference is more clearly pronounced. From comparative analysis of TCs satellite images with geological maps and karst morphological maps we conclude that some of bottoms of big karst forms are almost clearly defined with the brightness color scheme like limestones breccia-conglomerates or terra rossa bottoms of big poljes and big dolines between greenness - wetness color scheme of slopes especially those of limestones or dolomites as well in contact with those developed along the faults.

Ksiromero is not a classic limestone bedrock karstic area. The breccia - conglomerate carbonate geology background makes this area unusual due to the size of its karst landforms, type of vegetative cover, lack of a significant surface hydrological network, which make it difficult to remotely image karst features. In contrast, classical karst regions have limestone and dolomites bedrock where the variation in soil reflectance, green vegetation, and soil moisture more clearly expresses karst landforms with the TCs method.

\section{References}

Bosák P., Ford D.C., Glazek J., Horacek I. (Eds.) (1989) Paleokarst-a systematic and regional view, Academia Prague, Czechoslovakia, 725 p.

Crist E.P., Laurin R., Cicone R.C. (1986) Vegetation and Soils Information Contained in Transformed Thematic Mapper Data. Paper presented at International Geosciences and Remote Sensing Symposium (IGARSS)' 86 Symposium, ESA Publications Division, ESA SP-254.

Crist E.P., Kauth R.J. (1986) The Tasseled Cap De-Mystified. Photogrammetric Engineering \& Remote Sensing 52 (1): 81-86.

Crist E.P.; Cicone R.C., (1984) A Physically-Based Transformation of Thematic Mapper Data - The TM Tasseled Cap. IEEE Transactions of Geoscience and Remote Sensing 22(3), 256-263.

Čar J. (2001) Structural bases for shaping of dolines. Acta Carsologica, 30(2), 239-256.

Ford D., Williams P. (2007) Karst Hydrology and Geomorphology. John Wiley \& Sons, LTD, West Sussex, England

Horne J.H. (2003) A tasseled cap transformation for IKONOS images. ASPRS Annual Conference Proceedings. American Society of Photogrammetry and Remote Sensing, Anchorage, Alaska -USA, 2003; pp. 1-7

Institute of Geology and Mineral Exploration, IGME (1986) Geological map of Greece: Astrakos Sheet. Institute of Geology and Mineral Exploration, 1 sheet.

Institute of Geology and Mineral Exploration, IGME (1987) Geological map of Greece: Amphilochia Sheet. Institute of Geology and Mineral Exploration, 1 sheet.

Karakitsos V. (1992) Ouverture et Inversion Tectonique du Bassin Ionien (Epire, Grece). Annales Geologues des pays Helleniques, 35, 185-318.

Kauth R.J., Thomas G.S. (1976) The tasseled cap: A graphic description of the spectral-temporal development of agricultural crops as seen by Landsat, Final proceedings: Second international symposium on machine processing of remotely sensed data, Purdue University, West Lafayette, pp. 41-51.

Klimchouk A. (2000) Speleogenesis - Evolution of Karst Aquifers. National Speleological Society, Alabama U.S.A.

Lavreau J. (1991) De-Hazing Landsat Thematic Mapper Images. Photogrammetric Engineering \& Remote Sensing 57 (10): 1297-1302. 
Lillesand T.M., Kiefer R.W. (1987) Remote Sensing and Image Interpretation. New York: John Wiley \& Sons, Inc.

Richards A. (1999) Remote Sensing digital image analysis: An introduction, Springer-Verlag, Berlin, p. 240.

Sabins F.F. (1996) Remote Sensing: Principles and Interpretation, W. H. Freeman and Company, New York, 3rd ed., 494 p.

Taylor P.J. (1977) Quantitative Methods in Geography: An Introduction to Spatial Analysis. Boston, Massachusetts: Houghton Mifflin Company.

Underhill J.R. (1988) Triassic evaporates and Plio-Quaternary diapirism in western Greece. Journal of the Geological Society, 145(2), 269-282.

Veni G. (1999) A geomorphological strategy for conducting environmental impact assessments in karst areas. Geomorphology, 31, 151-180. 